\title{
Facile green synthesis of variable metallic gold nanoparticle using Padina gymnospora, a brown marine macroalga
}

\author{
M. Singh $\cdot$ R. Kalaivani $\cdot$ S. Manikandan • \\ N. Sangeetha $\cdot$ A. K. Kumaraguru
}

Received: 13 February 2012/ Accepted: 30 March 2012/Published online: 15 April 2012

(C) The Author(s) 2012. This article is published with open access at Springerlink.com

\begin{abstract}
The process of development of reliable and eco-friendly metallic nanoparticles is an important step in the field of nanotechnology. To achieve this, use of natural sources like biological systems becomes essential. In the present work, extracellular biosynthesis of gold nanoparticles using Padina gymnospora has been attempted and achieved rapid formation of gold nanoparticles in a short duration. The UV-vis spectrum of the aqueous medium containing gold ion showed peak at $527 \mathrm{~nm}$ corresponding to the plasmon absorbance of gold nanoparticles. Scanning electron microscopy showed the formation of welldispersed gold nanoparticles. FTIR spectra of brown alga confirmed that hydroxyl groups present in the algal polysaccharides were involved in the gold bioreduction. AFM analysis showed the results of particle sizes $(53-67 \mathrm{~nm})$ and average height of the particle roughness $(60.0 \mathrm{~nm})$. X-ray diffraction (XRD) spectrum of the gold nanoparticles exhibited Bragg reflections corresponding to gold nanoparticles. This environment-friendly method of biological gold nanoparticle synthesis can be applied potentially in various products that directly come in contact with the human body, such as cosmetics, and foods and consumer goods, besides medical applications.
\end{abstract}

Keywords Chloroauric acid P Padina gymnospora . Marine macroalgae $\cdot$ Extracellular synthesis .

Biological synthesis

M. Singh $(\varangle) \cdot$ R. Kalaivani $\cdot$ S. Manikandan · N. Sangeetha .

A. K. Kumaraguru

Department of Marine and Coastal Studies,

Madurai Kamaraj University, Madurai 625021,

Tamilnadu, India

e-mail: lookformanoj@gmail.com

\section{Introduction}

Currently, there is a growing need to develop environmentally benign nanoparticle synthesis process that does not use any toxic chemicals in the synthesis. An important aspect of nanotechnology which has a big challenge, is the development of metal nanoparticles synthesis. Nanoparticles considered as particles with a size of up to $100 \mathrm{~nm}$, exhibit completely new or improved properties as compared to the larger particles of the bulk material with specific characteristics, such as size, distribution, and morphology (Willems 2005). Nanoparticles of noble metals, such as gold, silver, and platinum, are widely applied in products that directly come in contact with the human body, such as shampoos, detergent, soaps, shoes, cosmetic products, and toothpaste, besides medical and pharmaceutical applications. Gold has a long history of use. Red colloidal gold has been used as medicine for revitalization in China and India (Bhattacharya and Murkherjee 2008). Gold nanoparticles have found use in diagnostic and drug delivery applications (Bhumkar et al. 2007). Biological methods for metallic nanoparticle synthesis using microorganisms, enzymes, and plants or plant extracts have been suggested as possible eco-friendly alternatives to chemical and physical methods (Mohanpuria et al. 2008). Using plants for nanoparticle synthesis can be more advantageous over other biological processes because it eliminates the elaborate process of maintaining cell cultures and can also be suitably scaled up for large-scale nanoparticle synthesis (Shankar et al. 2004). Gardea-Torresdey et al. (2002, 2003) demonstrated gold and silver nanoparticle synthesis within live alfalfa plants from solid media. Biosynthesis of $\mathrm{Au}$ nanoparticles by plants, such as Azadirachta indica (Shankar et al. 2004), Medicago sativa (Gardea-Torresdey et al. 2002), Aloe vera (Chandran et al. 2006), 
Cinnamomum camphora (Huang et al. 2007), Pelargonium graveolens (Shankar et al. 2003), Cymbopogon flexuosus (Shankar et al. 2004), Tamarindus indica (Ankamwar et al. 2005), Coriandrum sativum (Narayanan and Sakthivel 2008) have also been reported, thus extracellular nanoparticle synthesis using plant leaf extracts rather than whole plants would be more economical owing to easier downstream processing. Review of literature revealed that synthesis of nanoparticles using marine algae has been unexplored, which attracted our interest in the present investigation.

Herein, an environmental-friendly method for the aqueous synthesis and stabilization of gold nanoparticles by the reduction of aqueous $\mathrm{AuCl}_{4}{ }^{-}$ions using the leaf broth of Padina gymnospora is reported. Padina gymnospora belongs to the family Dictyotaceae. Interestingly, this is the first report about the synthesis of highly stable gold nanoparticles using marine alga ( $P$. gymnospora).

\section{Materials and methods}

Chemicals and collection of plant materials

Chloroauric acid $\left(\mathrm{HAuCl}_{4}\right)$ was purchased from SigmaAldrich (Bangalore, India). The healthy, matured leaves of P. gymnospora were collected from Pudhumadam Coast of "Gulf of Mannar" Tamil Nadu, India.

Synthesis of gold nanoparticles

Marine macroalga, $P$. gymnospora leaves were collected and thoroughly washed with double distilled water $\left(\mathrm{ddH}_{2} \mathrm{O}\right)$ and shade-dried in dust-free condition for 1 week at room temperature before being ground to fine powder. The leaf broth solution was prepared by taking $5 \mathrm{~g}$ of thoroughly washed and finely cut leaves in a $300-\mathrm{mL}$ Erlenmeyer flask along with $100 \mathrm{~mL}$ of sterile distilled water and then boiling the mixture for 5 min before finally decanting it. The solutions were stored at $4{ }^{\circ} \mathrm{C}$ and used within a week. Typically, $10 \mathrm{~mL}$ of leaf broth was added to $190 \mathrm{~mL}$ of $1 \mathrm{mM}$ aqueous $\mathrm{HAuCl}_{4}$ solution for the reduction of $\mathrm{Au}^{3+}$ ions.

Purification of gold nanoparticles

The broth containing the nanoparticles were centrifuged at $15,000 \mathrm{rpm}$ for $15 \mathrm{~min}$ to obtain the dry powder of the gold nanoparticles following which the pellet was redispersed in sterile distilled water to get rid of any biological molecule. The process of centrifugation and redispersion in sterile deionized distilled water was repeated thrice to obtain better separation of entities from the metal nanoparticles.
The purified pellets were then freeze-dried using a lyophilizer (Micro Modulyo 230 freeze dryer, Thermo Electron Corporation, India).

UV-visible spectral analysis

The colour change was observed in the chloroauric acid solution incubated with cell-free culture filtrate. The bioreduction of $\mathrm{AuCl}_{4}{ }^{-}$ions in solution was monitored by periodic sampling of aliquots $(0.1 \mathrm{~mL})$ of aqueous component and measuring the UV-vis spectra of the solution in 10-mm-optical-path-length quartz cuvettes with an UV1601 Schimadzu spectrophotometer at a resolution of $1 \mathrm{~nm}$ between 400 and $800 \mathrm{~nm}$ with a scanning speed of $1,856 \mathrm{~nm} / \mathrm{min}$. The nanoparticle solution was diluted to 20 times with deionized water to avoid errors due to high optical density of the solution.

Optimization of physiochemical parameters for biosynthesis of nanoparticles

Influence of temperature, $\mathrm{pH}$, salinity, sources of carbon and nitrogen on the production of silver nanoparticle was optimized by varying the parameters one at a time, such as temperature $\left(25-95^{\circ} \mathrm{C}\right), \mathrm{pH}(4,5,6,7,8,9,10,11$, and 12) and incubation period $(0-20 \mathrm{~h})$. Sample of $1 \mathrm{ml}$ was withdrawn at different time intervals and the absorbance was measured at $527 \mathrm{~nm}$.

Fourier transform infrared (FTIR) spectroscopy

The bioreduced chloroauric acid solution was centrifuged at 15,000 rpm for $15 \mathrm{~min}$, and the pellet was washed with deionized water to get rid of the free proteins/enzymes that were not capping the gold nanoparticles. Thereafter, the purified suspension was freeze-dried to obtain dry powder. The dried powder was analyzed using FTIR. The samples were dried and ground with $\mathrm{KBr}$ pellets, and analyzed on a Thermo Nicolet model 6700 spectrum instrument. A disk of $50 \mathrm{mg}$ of $\mathrm{KBr}$ was prepared with mixture of $2 \%$ finely dried samples and then examined under IR-spectrometer. Infrared spectra were recorded in the region of $500-4,500 \mathrm{~cm}^{-1}$.

Atomic force microscopy (AFM)

A thin film of the sample was prepared on a cover slip by dropping $0.1 \mathrm{ml}$ of the sample on the slide, and allowed to dry for $30 \mathrm{~min}$. The slides were then scanned with AFM (APE Research-model no: A100SGS). The AFM characterization was carried out in ambient temperature in non-contact mode using silicon nitrate tips with varying resonance frequencies. 
Scanning electron microscopy (SEM)

Synthesised gold nanoparticle solution was centrifuged at $15,000 \mathrm{rpm}$ for $30 \mathrm{~min}$. The pellet was resuspended in $10 \mathrm{ml}$ sterile deionised water and centrifugation process was repeated for three times. Then, the pellet was mixed with $10 \mathrm{ml}$ deionised water and kept on sonicator for prevent aggregation of gold ions. The resultant solution was lyophilized. The nanoparticles were mounted on the copper stubs, and the images were studied using scanning electron microscope (SEM), (HITACHI (Model: S-3400N) with secondary electron detectors at an operating voltage of $30 \mathrm{kV}$.

X-ray diffraction (XRD) studies

The bioreduced chloroauric acid solution was drop-coated onto glass substrate and powder X-ray diffraction measurements were carried out on a PANalytical X'pert PRO $\mathrm{X}$-ray diffractometer. The pattern was recorded by $\mathrm{Cu} \mathrm{K} \alpha$ radiation with $\lambda$ of $1.5406 \AA$ and nickel monochromator filtering the wave at tube voltage of $40 \mathrm{kV}$ and tube current of $30 \mathrm{~mA}$. The scanning was done in the region of $2 \theta$ from 20 to $80^{\circ}$ at $0.02^{\circ} / \mathrm{min}$ and the time constant was $2 \mathrm{~s}$.

\section{Results and discussion}

UV-vis analysis of gold nanoparticles

UV-visible spectroscopy is an important technique to determine the morphology and stability of nanoparticles. The formation of gold nanoparticles by the cell-free filtrate was observed with change of colour from yellow to rubyred (Shankar et al. 2004), which is the characteristic for gold nanoparticles formation due to the excitation of surface plasmon vibrations in gold nanoparticles. It is well known that the optical properties of the metal nanoparticles are strongly dependent on their size and shape. According to the Mie theory, the small gold nanoparticles exhibit only one surface plasmon resonance (SPR) absorption band, whereas anisotropic particles show two or three SPR bands. Figure 1 shows UV-vis spectra of the aqueous chloroauric acid. In the case of gold ion reduction, the bands corresponding to the SPR occurred at $527 \mathrm{~nm}$. The solution was extremely stable without any aggregation for 1 month after reaction.

\section{Optimization of physiochemical parameters}

Nanoparticle synthesis in terms of colour intensity of $P$. gymnospora leaf broth filtrate was examined at different $\mathrm{pH}$ (4-12), incubation time (0-20 h), and temperature

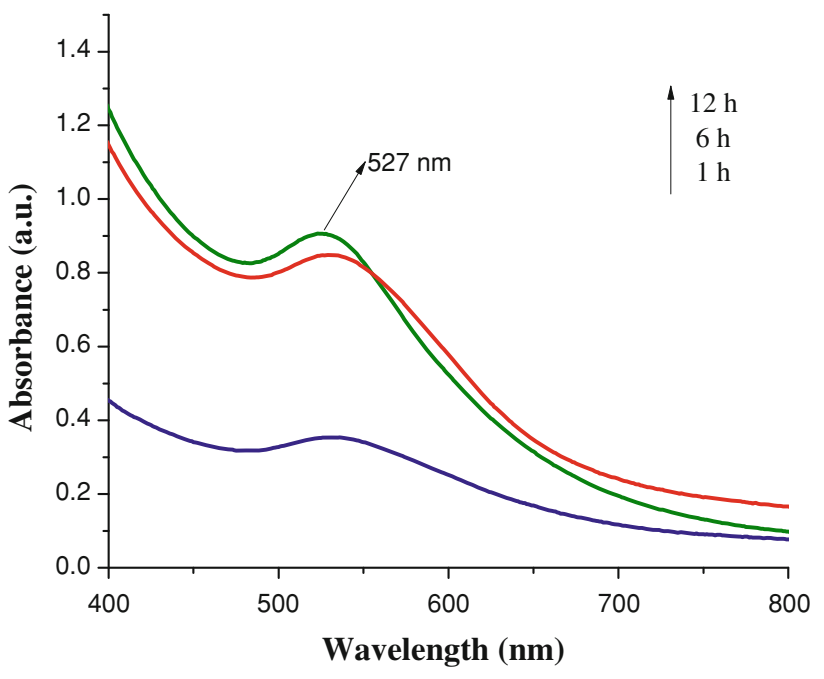

Fig. 1 UV-vis spectrum recorded for gold nanoparticles formed using marine alga Padina gymnospora

$\left(25-95{ }^{\circ} \mathrm{C}\right)$. The absorbance spectra exhibited peak at $527 \mathrm{~nm}$, at which, the highest optical density was found at $12 \mathrm{~h}$ of incubation time, $\mathrm{pH} 10$, and temperature of $75^{\circ} \mathrm{C}$ (Fig. 2a-c). The increase in colour intensity of culture filtrate was due to increasing number of nanoparticles formed as a result of reduction of gold ions present in the aqueous solution. In the present study, $\mathrm{pH} 10.0$ supported the maximum synthesis of gold nanoparticles (Fig. 2b). The fact that gold nanoparticles peak remained close to $527 \mathrm{~nm}$ even after $12 \mathrm{~h}$ of incubation (Fig. 2c) indicates that nanoparticles synthesized are well dispersed in solution. The increase in the reaction rate with the reaction temperature was also reported by Rai et al. in case of gold nanotriangle synthesis using lemongrass extract (Rai et al. 2006).

\section{FTIR analysis of gold nanoparticles}

The FTIR analysis revealed the strong bands at 3,338 , $2,929,2,850,1,629,1,379$, and $1,024, \mathrm{~cm}^{-1}$ shown in (Fig. 3) along with other weak bands. The band at $1,020 \mathrm{~cm}^{-1}$ corresponds to of $\mathrm{C}-\mathrm{N}$ stretching vibration of aliphatic amines. The band at 1,328 belongs $\mathrm{cm}^{-1}$ to weaker aliphatic nitro compound. The band obtained at $1,625 \mathrm{~cm}^{-1}$ corresponds to amide one arisen due to carbonyl stretch in proteins. The both bands at 2,852 and $2,953 \mathrm{~cm}^{-1}$ can be assigned as carbonyl group and secondary amines, respectively. The intense broad band absorbance at $3,434 \mathrm{~cm}^{-1}$ is the characteristics of the hydroxyl functional group in alcohol and phenol compounds. The band at $559 \mathrm{~cm}^{-1}$ is a very weak band. This indicates that gold nanoparticles synthesized using $P$. gymnospora leaf extract are surrounded by some proteins and secondary metabolites, such as alkaloids having 
Fig. 2 Absorption spectrum for gold nanoparticles synthesis using marine alga Padina gymnospora at a effect of $\mathrm{pH}$, b effect of incubation time, and c effect of temperature
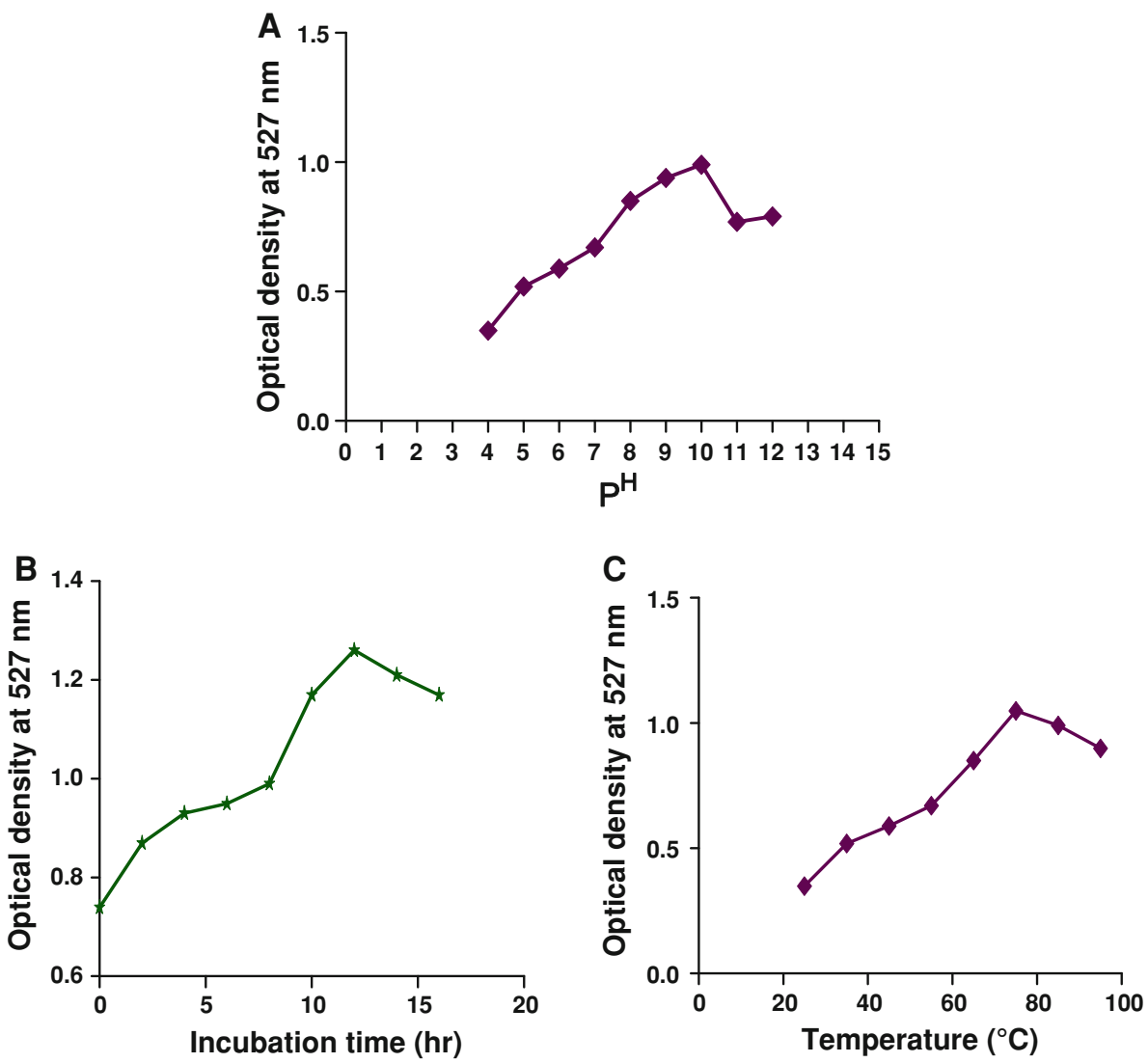

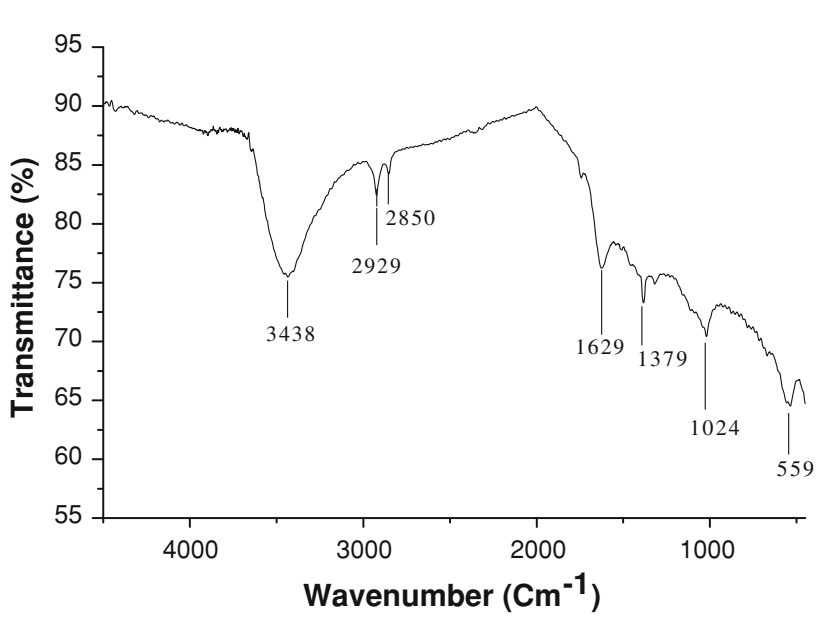

Fig. 3 FTIR spectra of gold nanoparticles synthesized from Padina gymnospora leaf broth

functional groups of hydroxyl, amines, alcohols, phenol and carboxylic acids.

The FTIR spectrums of the hydroxyl groups $(\mathrm{OH})$ are very abundant in polysaccharides of the algal cell wall (Davis et al. 2003) and its participation in the reduction process was confirmed by FTIR analysis of the biomass after gold recovery. Algal pigments, such as fucoxanthins, a kind of carotenoids rich in hydroxyl groups, could also have participated in the gold reduction. These pigments have reductive properties and are released to solution by diffusion (Kuyucak and Volesky 1989). These soluble elements could have acted as capping agents preventing the aggregation of nanoparticles in solution, playing a relevant role in their extracellular synthesis and shaping (Huang et al. 2007).

\section{Analysis of gold nanoparticle in AFM and SEM}

The obtained morphology revealed the fact that the synthesized gold nanoparticles are almost spherical without other observable nanostructures morphologies, as confirmed by absorbance spectrum. The size of the spherical gold nanoparticles obtained from AFM has a broad size distribution in the range of nanometers, which also can be correlated with the observed broad area of the absorbance peak. The particles are not highly monodisperse but seem non-agglomerated as this could be due to the fact that the presence of some important bio-organic compounds in the plant extract seems to act as a ligand which effectively stabilizes the formed gold nanoparticles. Figure 4 shows a three- and two-dimensional view of sample surface over a $3 \times 3 \mu \mathrm{m}$ scan which shows non-agglomerated, polydispersed distribution with a uniform height distribution (around $53 \mathrm{~nm}$ ) of the immobilized samples on the 
substrate, indicating a uniform coating. The average height of the particle roughness was $(60.0 \mathrm{~nm})$. The gold nanoparticles are spherical in shape with size ranging from 53 to $67 \mathrm{~nm}$, as evident by SEM studies (Fig. 4).

The morphology with the reaction temperature can be discussed in relation to the reaction rate. At higher temperatures, most gold ions first form nuclei, and the secondary growth of the particles stops because the reaction rate is very high. Figure 5 shows SEM images of the gold nano powder having spherical morphology with traces of agglomeration. The obtained size distribution is similar to that of AFM. The range of particle size of the nanoparticle is found to be in between 53 and $67 \mathrm{~nm}$.

\section{$\mathrm{X}$-ray diffraction $(\mathrm{XRD})$ analysis}

The X-ray diffraction pattern (XRD) gold nanoparticles are shown in Fig. 6 synthesized using leaf of $P$. gymnospora. A number of Bragg reflections with $2 \theta$ values of 38.11, 44.25, 64.08 , and 77.5 which correspond to the (111), (200), (220), and (311) sets of lattice planes are observed which are indexed to the face-centered cubic structures for gold. The broadening of Bragg's peaks indicates the formation of nanoparticles. A few intense additional and yet unassigned peaks were also noticed in the vicinity of characteristic peaks of gold $(27.1,32.5,46.05)$. These sharp peaks might

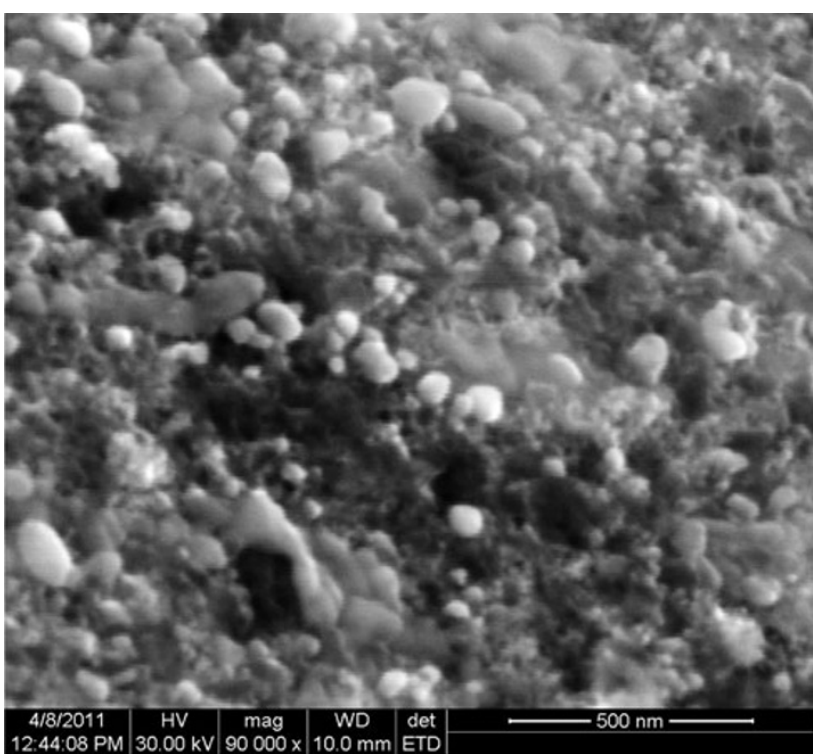

Fig. 5 SEM images of the gold nanoparticles formed by the reaction of $1 \mathrm{mM} \mathrm{HAuCl}_{4}$ and $5 \%$ Padina gymnospora broth at reaction temperatures $95^{\circ} \mathrm{C}$

have resulted from some bio-organic compounds/proteins in the nanoparticle during the synthesis (Gardea-Torresdey et al. 2002). The presence of these external peaks, which are unassigned, did not alter the Bragg reflection peaks dedicated to gold, indicating that their presence could also be
Fig. 4 AFM images obtained from lyophilized sample of gold nanoparticle obtained from $5 \%$ of Padina gymnospora leaf extract indicate the different sizes of nanoparticles between 53 and $67 \mathrm{~nm}$ ranges
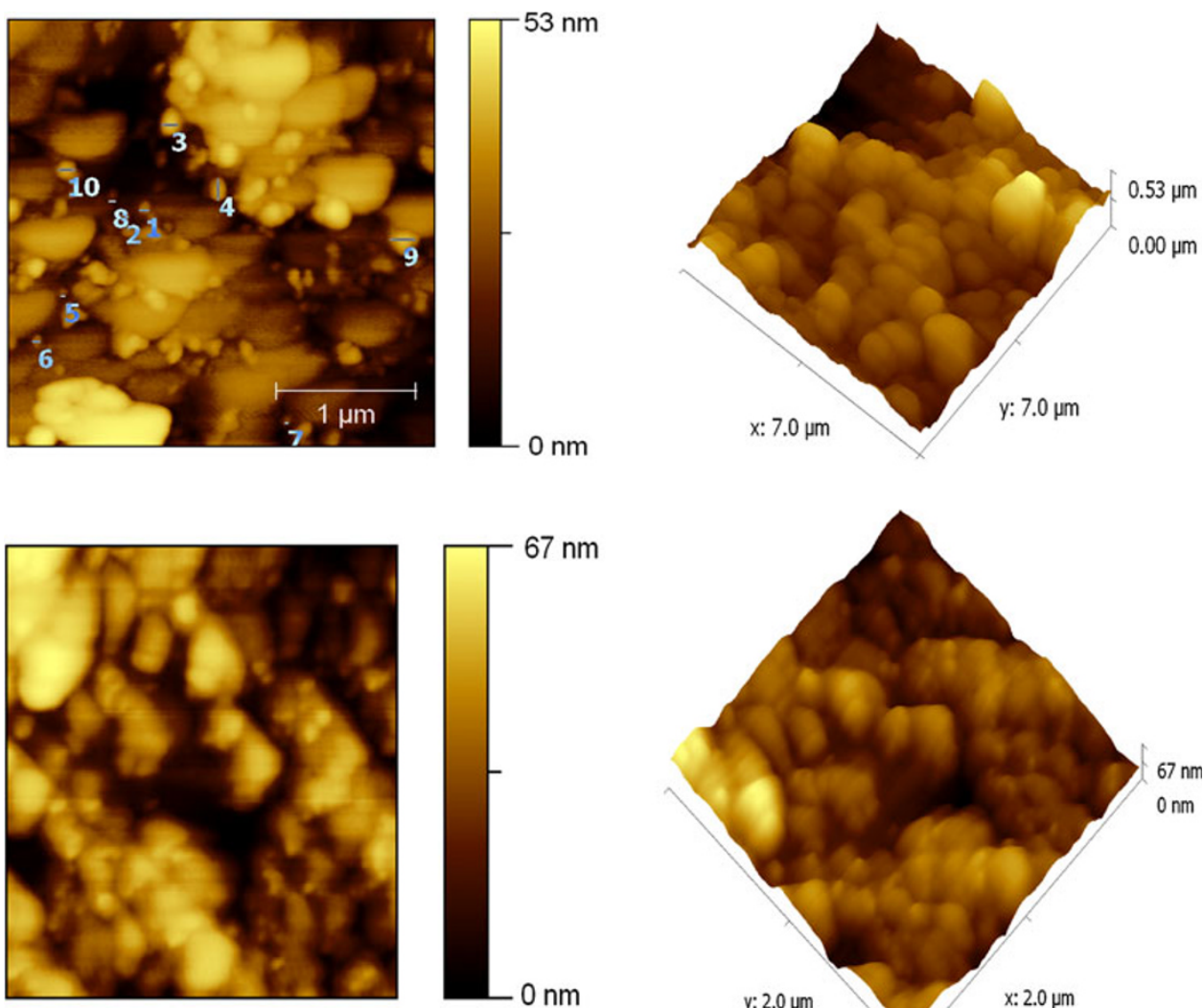

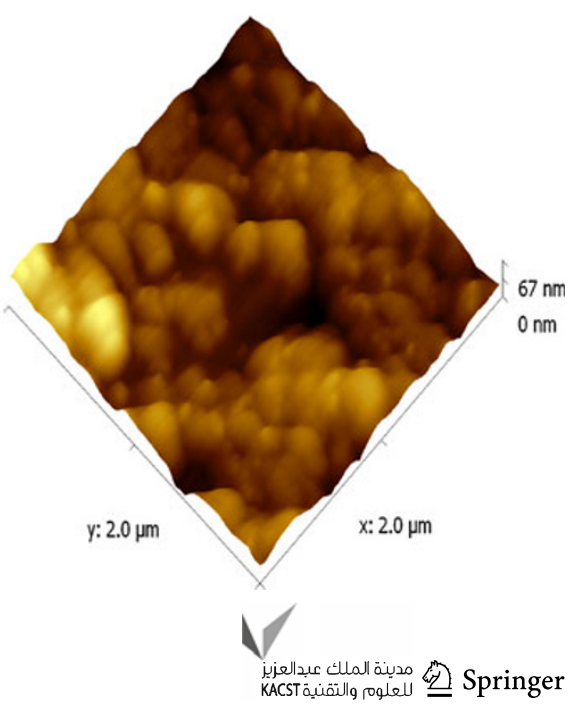




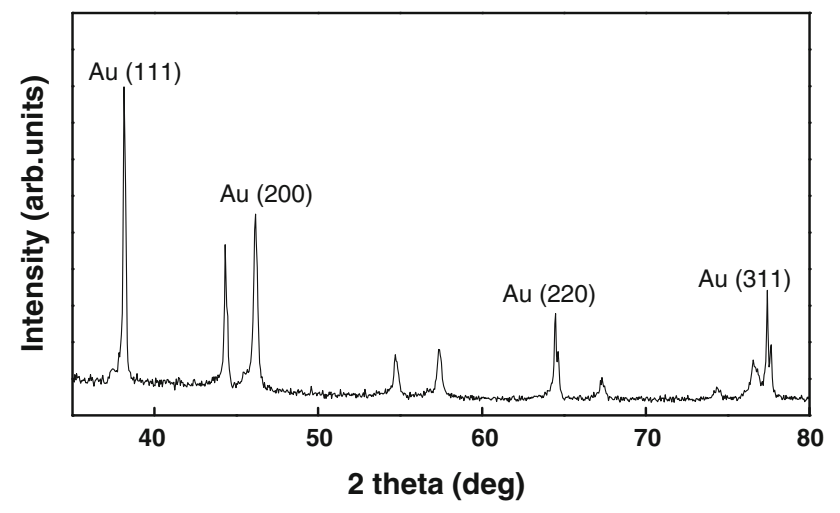

Fig. $6 \mathrm{X}$-ray diffraction pattern of gold nanoparticles formed by the reaction of $1 \mathrm{mM} \mathrm{HAuCl}_{4}$ and $5 \%$ Padina gymnospora

responsible for the stabilized gold nanoparticles. The XRD pattern thus clearly illustrates that the gold nanoparticle synthesized by the green method are crystalline in nature.

\section{Discussion}

Application of gold nanoparticles in these fields is dependent on the ability to synthesize particles with chemical composition, shape, size, and monodispersity. Further, the particles should be chemically stable without undergoing degradation, such as partial oxidation or undesired sintering. Currently, there are several physical and chemical methods for the synthesis of metallic nanoparticles that are followed by the material scientists (Edelstein and Cammarata 1996). However, development of simple and eco-friendly (green technology) synthetic route would help in promoting further interest in the synthesis and application of metallic nanoparticles. In this regard, $P$. gymnospora proves to be an important biological component in the right direction for extracellular biosynthesis of stable gold nanoparticles.

It was observed that the reduction of the $\mathrm{AuCl}_{4}{ }^{-}$ions during exposure to $P$. gymnospora powder may be easily followed by UV-vis spectroscopy. It has been well established that SPR of metallic gold nanoparticles exhibit ruby-red colour and gives rise to an absorption band at 510-540 nm (Shankar et al. 2004). The fact that gold nanoparticles peak remained close to $527 \mathrm{~nm}$ even after $12 \mathrm{~h}$ of incubation indicates that the particles were well dispersed in the solution, and there was not much aggregation. The rate of synthesis to gold nanoparticles conversion reached to $100 \%$ with increase in reaction temperatures; however, at room temperature the conversion rate was very slow compared to other temperature range. AFM image of synthesized AuNPs shows the spherical nature and gold nanoparticles with very good monodispersity using Thermonospora sp. (Ahmad et al. 2003). The particles are not highly monodisperse but seem to be nonagglomerated, and this could be due to the presence of some bio-organic compounds in the plant extract that seems to act as a ligand which effectively stabilizes the formation of gold nanoparticles.

The formation of pure metallic nanoparticles and bimetallic nanoparticles by reduction of the metal ions is possibly facilitated by reducing sugars and/or terpenoids present in the neem leaf broth (Shankar et al. 2004). The presence of extracellular polysaccharides in seaweed S. wightii is $35 \%$ (Davis et al. 2003), which may facilitate the stabilization of nanoparticles. The particle size of AuNPs was found to be of different range. The morphology of the particles formed consists of a mixture of gold nanoprisms and spheres with FCC (111) structure of gold. The XRD pattern thus clearly illustrates that the gold nanoparticle synthesized by the green method are crystalline in nature. This study will therefore lead to the development of an easy bioprocess for synthesis of gold nanoparticles and opens up a new possibility of very conveniently synthesizing $\mathrm{Au}$ nanoparticles using natural products which will be useful in biomedical applications.

\section{Conclusion}

In this paper we report a green chemistry approach which is an eco-friendly method for the synthesis of Au nanoparticles by the reduction of aqueous $\mathrm{AuCl}_{4}{ }^{-}$ions using $P$. gymnospora leaf broth. An important potential benefit of the described method of synthesis of nanoparticles using marine algae is that they are quite stable in solution and this is a very important advantage over other biological methods currently in use. Although the primary purpose of this research has been made towards cancer therapeutics, these results also open up the possibility for future work involving other applications with proteins or other biologically important molecules. Certainly, mixed-monolayer AuNPs present an exciting nanoparticle platform for future.

Acknowledgments The authors convey their sincere thanks to Indian Council of Medical Research (ICMR) for their financial support to carry out this project.

Open Access This article is distributed under the terms of the Creative Commons Attribution License which permits any use, distribution, and reproduction in any medium, provided the original author(s) and the source are credited.

\section{References}

Ahmad A, Senapati S, Islam Khan M, Kumar R, Sastry M (2003) Extracellular biosynthesis of nanoparticle. Langmuir 19: $3550-3553$ 
Ankamwar B, Chaudhary M, Sastry M (2005) Gold nanotriangles biologically synthesized using tamarind leaf extract and potential application in vapor sensing. Synth React Inorg Metal-Org Nano-Metal Chem 35:19-26

Bhattacharya R, Murkherjee P (2008) Biological properties of "naked" metal nanoparticles. Adv Drug Deliv Rev 60: $1289-1306$

Bhumkar DR, Joshi HM, Sastry M, Pokharkar VB (2007) Chitosan reduced gold nanoparticles as novel carriers for transmucosal delivery of insulin. Pharm Res 24:1415-1426

Chandran SP, Chaudhary M, Pasricha R, Ahmad A, Sastry M (2006) Synthesis of gold nanotriangles and silver nanoparticles using Aloe vera plant extract. Biotechnol Prog 22:577-583

Davis TA, Volesky B, Mucci A (2003) A review of the biochemistry of heavy metal biosorption by brown algae. Water Res 37: 4311-4330

Edelstein AS, Cammarata RC (eds) (1996) Nanomaterials: synthesis, properties and applications. IOP, Bristol

Gardea-Torresdey JL, Parsons JG, Gomez E, Peralta-Videa J, Troiani HE, Santiago P et al (2002) Formation and growth of $\mathrm{Au}$ nanoparticles inside live alfalfa plants. Nano Lett 2:397-401

Gardea-Torresdey JL, Gomez E, Peralta-Videa J, Parsons JG, Troiani HE, Santiago P et al (2003) Alfalfa sprouts: a natural source for the synthesis of silver nanoparticles. Langmuir 19:1357-1361

Huang J, Chen C, He N, Hong J, Lu Y, Qingbiao L, Shao W, Sun D, Wang XH, Wang Y, Yiang X (2007) Biosynthesis of silver and gold nanoparticles by novel sundried Cinnamomum camphora leaf. Nanotechnology 18:105-106

Kuyucak N, Volesky B (1989) Accumulation of gold by algal biosorbent. Biorecovery 1:189-204

Mohanpuria P, Rana NK, Yadav SK (2008) Biosynthesis of nanoparticles: technological concepts and future applications. J Nanopart Res 10:507-517

Narayanan KB, Sakthivel N (2008) Coriander leaf mediated biosynthesis of gold nanoparticles. Mater Lett 62:4588-4590

Rai A, Singh A, Ahmad A, Sastry M (2006) Role of halide ions and temperature on the morphology of biologically synthesized gold nanotriangles. Langmuir 22:736-741

Shankar SS, Ahmad A, Sastry M (2003) Geranium leaf assisted biosynthesis of silver nanoparticles. Biotechnol Prog 19: $1627-1631$

Shankar SS, Rai A, Ahmad A, Sastry M (2004a) Rapid synthesis of $\mathrm{Au}, \mathrm{Ag}$, and bimetallic Au core Ag shell nanoparticles using Neem (Azadirachta indica) leaf broth. J Colloid Interface Sci 275:496-502

Shankar SS, Rai A, Ankamwar B, Singh A, Ahmad A, Sastry M (2004b) Biological synthesis of triangular gold nanoprisms. Nat Mater 3:482-488

van den Wildenberg W (2005) Roadmap report on nanoparticles. W\&W Espana sl, Barcelona 